\title{
Review Article \\ Diverse Pharmacological Activities and Potential Medicinal Benefits of Geniposide
}

\author{
Yan-Xi Zhou, ${ }^{1,2}$ Ruo-Qi Zhang, ${ }^{1}$ Khalid Rahman $\left(\mathbb{D},{ }^{3}\right.$ Zhi-Xing Cao, \\ Hong Zhang $(1),{ }^{4}$ and Cheng Peng $\left(\mathbb{1}^{1}\right.$ \\ ${ }^{1}$ Pharmacy College, Chengdu University of Traditional Chinese Medicine, Chengdu 611137, China \\ ${ }^{2}$ Library, Chengdu University of Traditional Chinese Medicine, Chengdu 611137, China \\ ${ }^{3}$ School of Pharmacy and Biomolecular Sciences, Faculty of Science, Liverpool John Moores University, Liverpool L3 3AF, UK \\ ${ }^{4}$ Institute of Interdisciplinary Medical Sciences, Shanghai University of Traditional Chinese Medicine, Shanghai 201203, China
}

Correspondence should be addressed to Hong Zhang; hqzhang51@126.com and Cheng Peng; pengcchengd@126.com

Received 2 January 2019; Accepted 19 March 2019; Published 16 April 2019

Academic Editor: Jairo Kennup Bastos

Copyright (C) 2019 Yan-Xi Zhou et al. This is an open access article distributed under the Creative Commons Attribution License, which permits unrestricted use, distribution, and reproduction in any medium, provided the original work is properly cited.

\begin{abstract}
Geniposide is a well-known iridoid glycoside compound and is an essential component of a wide variety of traditional phytomedicines, for example, Gardenia jasminoides Elli (Zhizi in Chinese), Eucommia ulmoides Oliv. (Duzhong in Chinese), Rehmannia glutinosa Libosch. (Dihuang in Chinese), and Achyranthes bidentata Bl. (Niuxi in Chinese). It is also the main bioactive component of Gardeniae Fructus, the dried ripe fruit of Gardenia jasminoides Ellis. Increasing pharmacological evidence supports multiple medicinal properties of geniposide including neuroprotective, antidiabetic, hepatoprotective, anti-inflammatory, analgesic, antidepressant-like, cardioprotective, antioxidant, immune-regulatory, antithrombotic, and antitumoral effects. It has been proposed that geniposide may be a drug or lead compound for the prophylaxis and treatment of several diseases, such as Alzheimer's disease, Parkinson's disease, diabetes and diabetic complications, ischemia and reperfusion injury, and hepatic disorders. The aim of the present review is to give a comprehensive summary and analysis of the pharmacological properties of geniposide, supporting its use as a medicinal agent.
\end{abstract}

\section{Introduction}

Geniposide $\left(\mathrm{C}_{17} \mathrm{H}_{24} \mathrm{O}_{10}\right.$; Figure 1), a well-known iridoid glycoside compound, is one of the main bioactive components of traditional Chinese medicine Gardeniae Fructus, the dried ripe fruit of Gardenia jasminoides Ellis (Zhizi in Chinese). It has been isolated and identified in nearly 40 species of plants and most of which are medicinal herbs [1]. Over the past few decades, there has been a rapid growth in the information available on the pharmacological activities of geniposide. Studies have shown that geniposide displays a wide spectrum of in vitro and in vivo pharmacological effects, including neuroprotective, antidiabetic, hepatoprotective, anti-inflammatory, analgesic, antidepressant-like, cardioprotective, antioxidant, immune-regulatory, antithrombotic, and antitumoral effects (summarized in Table 1), and these pharmacological effects lay the foundation for geniposide of being a potential therapeutic agent for the treatment of several diseases, such as Alzheimer's disease (AD), Parkinson's disease (PD), diabetes and diabetic complications, ischemia and reperfusion injury, and hepatic disorders. The aim of the present review is to give a comprehensive summary and analysis of the pharmacological properties of geniposide, supporting the potential uses of geniposide as a medicinal agent.

\section{Pharmacology Actions}

2.1. Anti-Alzheimer's Disease Activity. AD is the most common neurodegenerative disorder of progressive cognitive decline in the aged population [2]. A number of studies have demonstrated the anti-AD activity of geniposide both in vitro and in vivo. Formaldehyde is neurotoxic, and long-term overdose increases the risk of $\mathrm{AD}$. An increase in the concentration of endogenous formaldehyde in the brain has been found to correlate with dementia in aging 


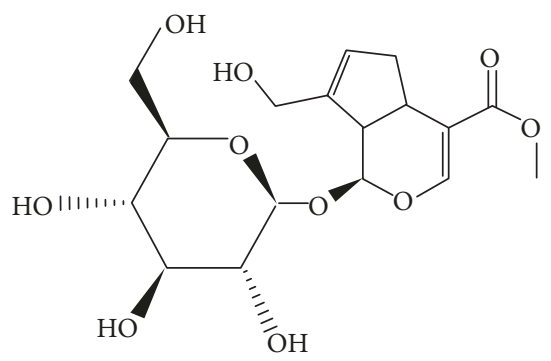

FIGURE 1: Chemical structure of geniposide.

people. In human neuroblastoma SH-SY5Y cells, treatment with geniposide at a concentration of $100 \mu \mathrm{M}$ ameliorated the morphology of formaldehyde- $(0.12 \mathrm{mM})$ injured cells. Furthermore, geniposide increased the production of the antiapoptotic gene $\mathrm{Bcl}-2$ at both mRNA and protein levels, while decreasing the expression of the proapoptotic gene P53, apoptotic executer caspase-3, and apoptotic initiator caspase9. Moreover, geniposide elevated the activity of intracellular antioxidants, including superoxide dismutase (SOD) and glutathione peroxidase (GSH-Px) [3]. Incubation of murine $\mathrm{N} 2$ a neuroblastoma cells with formaldehyde $(0.09 \mathrm{mM})$ for 24 h notably changed cell morphology, decreased cell viability, and promoted apoptosis, and these effects were reversed by supplementation with geniposide $(200 \mu \mathrm{M})$. In particular, geniposide remarkably ameliorated morphology and cell numbers, increased cell viability, upregulated the expression of Akt and $\mathrm{Bcl}-2$, and lowered the expression of FoxO3 and p53 [4].

Amyloid plaques composed of insoluble amyloid- $\beta(\mathrm{A} \beta)$ deposits are a characteristic pathological feature of $\mathrm{AD}$ and $\mathrm{A} \beta$ aggregated with oligomer is known to be able to induce cellular toxicity as well as cognitive impairment. Incubation with geniposide at $83.8 \mu \mathrm{M}$ reduced the cytotoxicity of $\mathrm{A} \beta(10 \mu \mathrm{M})$ in rat hippocampal neurons and promoted the outgrowth of neurites both in their length and in the dendrite number per neuron. Geniposide at 5, 100, and $200 \mu \mathrm{M}$ increased the cell viability of SY5Y-APP695sw cells treated with $\mathrm{A} \beta_{42}$ aggregates. Furthermore, geniposide at 100 $\mu \mathrm{M}$ promoted fibrillogenesis and increased the formation of high molecular masses of $\mathrm{A} \beta_{42}$ polymers, resulting in a decrease of the quantity and cytotoxicity of $\mathrm{A} \beta_{42}$ oligomers [5]. Moreover, geniposide averted $\mathrm{A} \beta_{1-42}$-induced cell injury in primary cultured cortical neurons [6]. The receptor for advanced glycation end products- (RAGE-) mediated signaling pathway is related to $\mathrm{A} \beta$-induced pathogenic responses. Geniposide at 50, 100, and $200 \mu \mathrm{M}$ suppressed RAGEmediated signaling (activation of extracellular regulated protein kinase (ERK) 1/2 and inhibited kappa B (I $\kappa$ B)/nuclear factor $-\kappa \mathrm{B}(\mathrm{NF}-\kappa \mathrm{B}))$ and attenuated the production of tumor necrosis factor- $\alpha$ (TNF- $\alpha$ ) and interleukin- $1 \beta$ (IL-1 $\beta$ ) in cultured BV2 microglia cells treated with $\mathrm{A} \beta_{1-42}(5 \mu \mathrm{M})$ [7]. In primary hippocampal neurons, it increased synaptic plasticity through alleviating the $\mathrm{A} \beta$-stimulated downregulation of long-term potentiation and elevating the miniature excitatory postsynaptic current amplitude and frequency. In APP/PS1 transgenic mice, intragastric administration of geniposide at $25 \mathrm{mg} / \mathrm{kg}$ for 3 months significantly inhibited RAGEmediated signaling, lowered the production of TNF- $\alpha$ and IL- $1 \beta$, and suppressed cerebral A $\beta$ accumulation. Moreover, geniposide ameliorated learning and memory deficits [8].

A large body of evidence indicates that insulin-degrading enzyme (IDE) plays an essential role in the degradation of $\mathrm{A} \beta$. Geniposide enhanced the expression of IDE in primary cortical neurons, and this effect was reversed by LY294002 (an inhibitor for phosphatidyl inositol 3-kinase, PI3K), GW9662 (an antagonist for peroxisome proliferator-activated receptor $\gamma, \operatorname{PPAR} \gamma$ ), AG1478 (an antagonist for epidermal growth factor receptor), H89 (an inhibitor for protein kinase A, PKA), and PP1 (an inhibitor for c-Src). Furthermore, it upregulated the phosphorylation of PPAR $\gamma$ and promoted the release of phosphorylated FoxO1 from nuclear fraction to the cytosol. In addition, geniposide directly activated the activity of IDE promoter in PC12 cells [9]. In neuroblastoma SH-SY5Y cells, incubation with geniposide at 1 and $10 \mu \mathrm{M}$ for $24 \mathrm{~h}$ notably augmented the level of IDE protein in a concentration-dependent manner [10].

Furthermore, an increasing number of studies have demonstrated that leptin has protective effect against AD. Geniposide treatment inhibited the level of $A \beta_{1-42}$ both in rat primary cortical neurons $(10 \mu \mathrm{M})$ and in APP/PS1 transgenic mice $(10,20$, and $40 \mathrm{mg} / \mathrm{kg}$, i.g.). Moreover, geniposide at $10 \mu \mathrm{M}$ induced the phosphorylation of Janus kinase 2 and signal transducer and activator of transcription 3 (STAT3), upregulated the protein level of ADAM10, and downregulated the expression of BACE1 in rat primary cortical neurons, and these effects were reversed by the preincubation with leptin antagonist $(50 \mathrm{ng} / \mathrm{mL})$ [11]. Formation of intracellular neurofibrillary tangle from hyperphosphorylated tau is one of the typical hallmark lesions of AD as well. Administration of geniposide enhanced the expression of leptin receptor and diminished the phosphorylation of tau both in rat primary cultured cortical neurons in vitro and in APP/PS1 transgenic mice in vivo. Additionally, geniposide at $10 \mu \mathrm{M}$ induced the phosphorylation of Akt at Ser-473 site and glycogen synthase kinase- $3 \beta$ (GSK-3 $\beta$ ) at Ser-9 site in primary cultured cortical neurons, and this effect of geniposide on Akt and GSK-3 $\beta$ as well as the effect of geniposide on tau phosphorylation could be inhibited by leptin antagonist (50 nM) [12]. Treatment with geniposide for 4 weeks also attenuated insulin deficiency-induced phosphorylated level of tau and acceleration of GSK-3 $\beta$ phosphorylation in the brain of APP/PS1 transgenic mice. It also augmented the effect of insulin on the phosphorylation of tau, Akt, and GSK-3 $\beta$ in primary cultured cortical neurons, and these effects were reversed by LY294002 [13]. In streptozotocin- (STZ-) induced AD model rats, injection of geniposide at $50 \mu \mathrm{M}$ to the lateral ventricle reduced STZ-induced spatial learning deficit, tau phosphorylation, and GSK-3 $\beta$ hyperactivity. Additionally, it inhibited STZ-stimulated neural pathology, including accumulation of vesicles in synaptic terminal, paired helical filament-like structures, abnormalities of endoplasmic reticulum (ER), and early stage of apoptosis [14].

Moreover, oxidative stress and mitochondrial dysfunction appear early and contribute to the disease progression in $\mathrm{AD}$. Preincubation with geniposide at $2.5,5$, and $10 \mu \mathrm{M}$ 


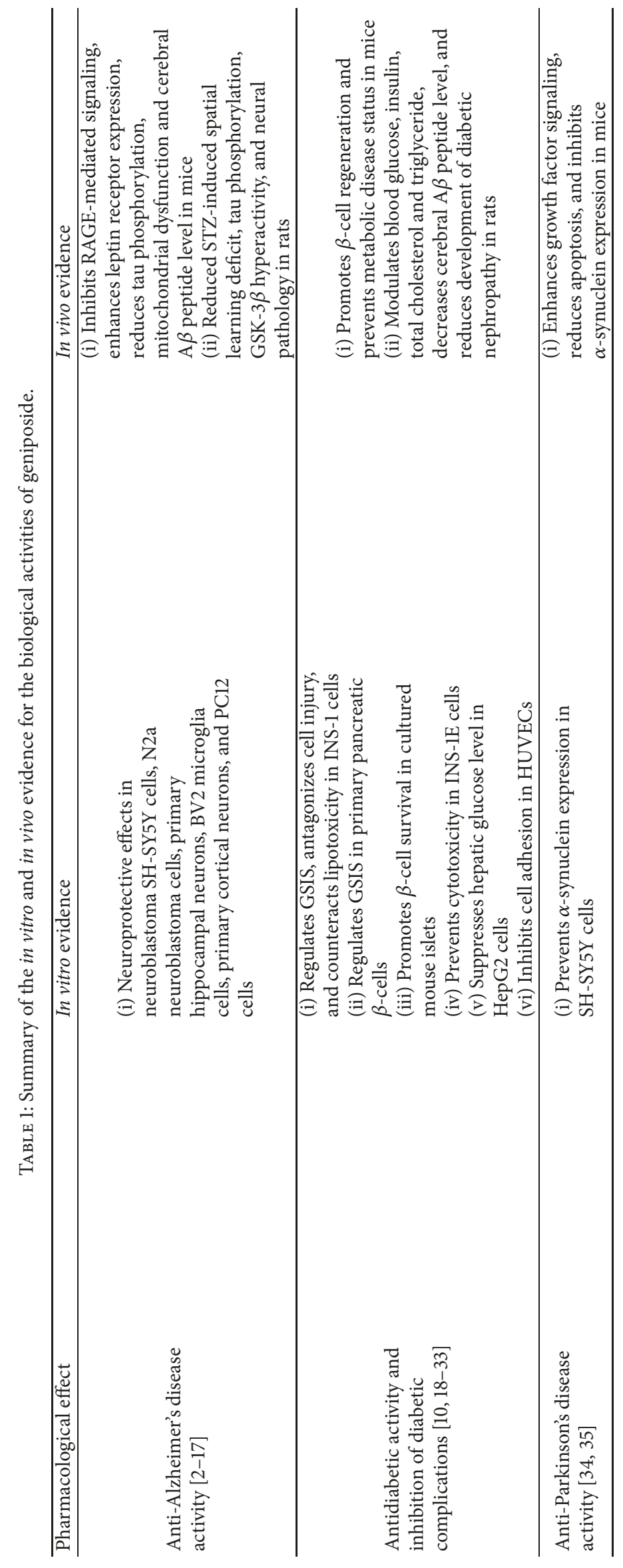




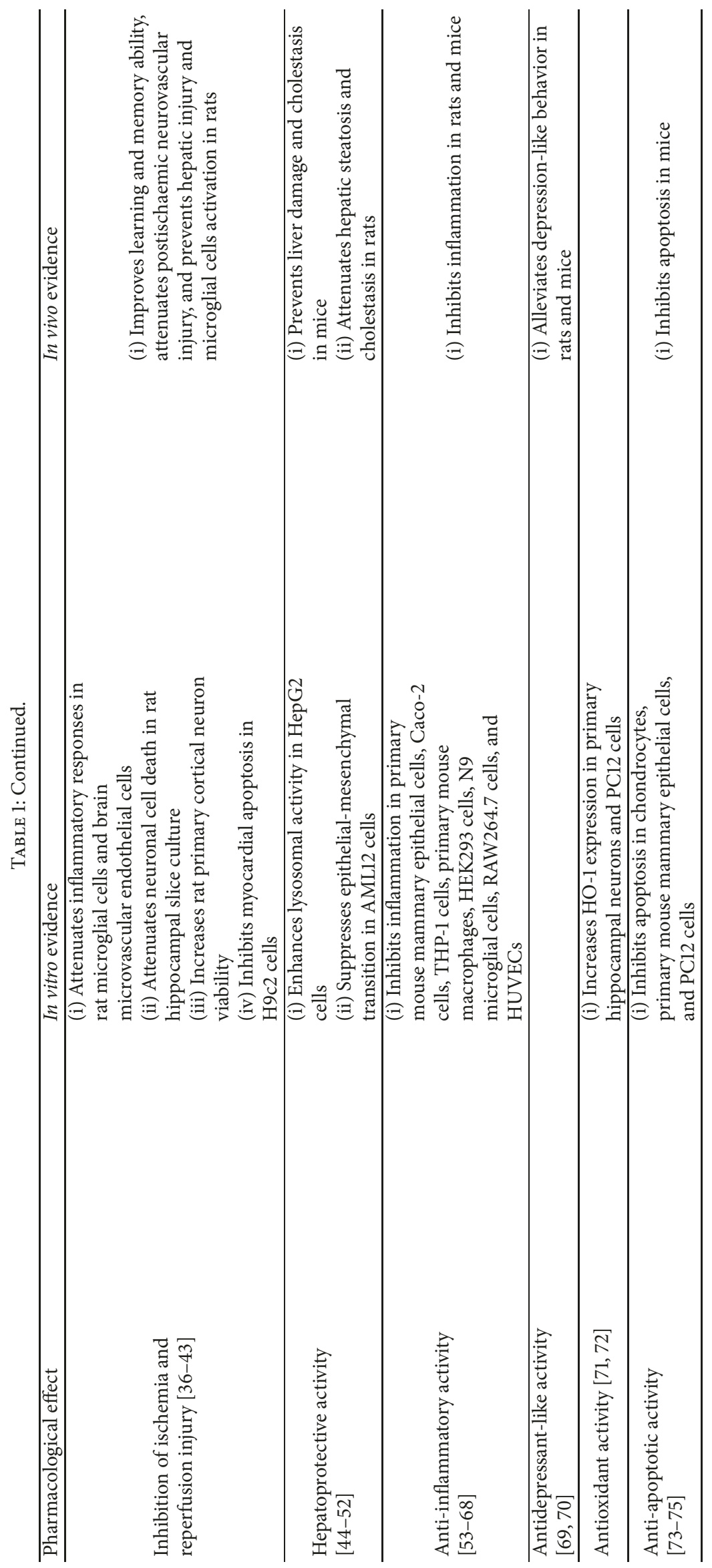




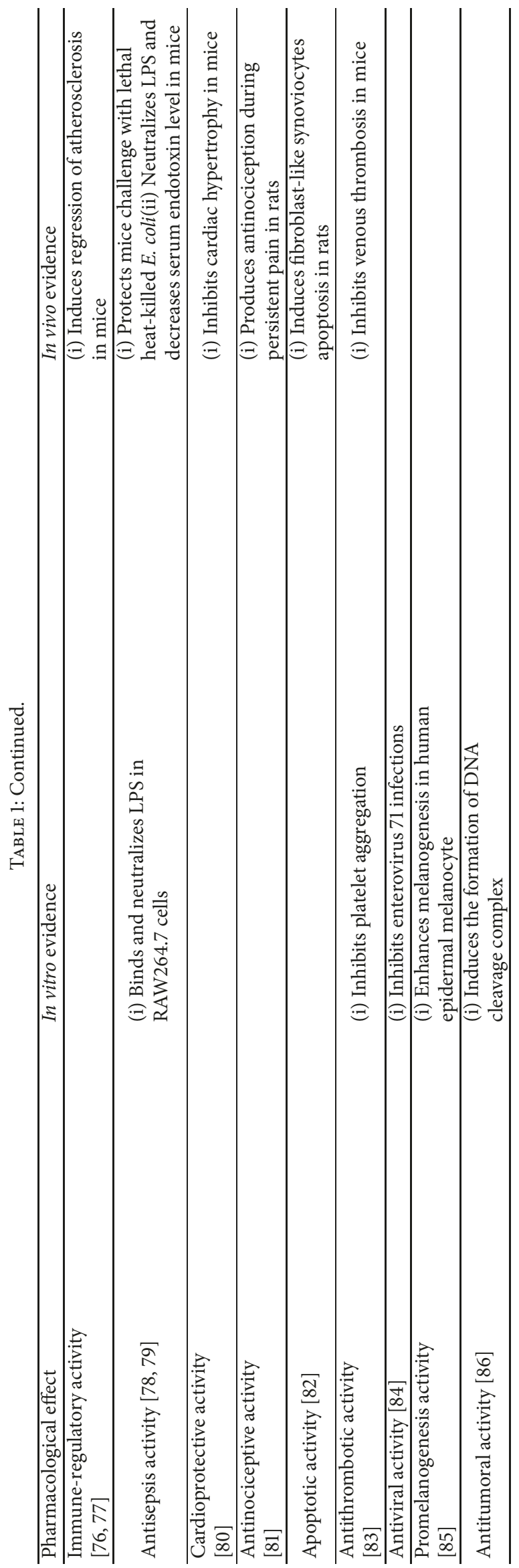


exerted protective effects against $\mathrm{A} \beta$-induced neuronal injury by blocking mitochondrial dysfunction and oxidative stress. In particular, geniposide ameliorated adenosine triphosphate (ATP) generation, mitochondrial membrane potential levels, cytochrome c oxidase and caspase-3/9 activity, attenuated reactive oxygen species (ROS) production and cytochrome c leakage and suppressed apoptosis in primary cultured mouse cortical neurons incubation with oligomeric $A \beta_{1-42}(5$ $\mu \mathrm{M})$ [15]. Intragastric administration of geniposide notably reduced mitochondrial dysfunction in APP/PS1 mice by inhibiting the mitochondrial oxidative stress and elevating the mitochondrial membrane potential and activity of cytochrome c oxidase [16]. Treatment with geniposide at 50 $\mu \mathrm{M}$ for $2 \mathrm{~h}$ stimulated the expression of Bcl- 2 in PC12 cells induced by $\mathrm{H}_{2} \mathrm{O}_{2}(100 \mu \mathrm{M})$, and this effect was retarded by preincubation with LY294002. Moreover, geniposide increased the phosphorylation of Akt308, Akt473, GSK-3 $\beta$, and phosphoinositide-dependent protein kinase 1 , suggesting that it protects against the oxidative damage induced by $\mathrm{H}_{2} \mathrm{O}_{2}$ in PC12 cells via PI3K signaling pathway [17]. Collectively, geniposide has the potential to be a drug or lead compound for the treatment of $\mathrm{AD}$.

2.2. Antidiabetic Activity and Inhibition of Diabetic Complications. Glucose-stimulated insulin secretion (GSIS) from pancreatic $\beta$ cells is one of the key mechanisms in regulating cellular adaptation demands to nutritional and metabolic variations. In rat pancreatic INS-1 cells in vitro, geniposide at $5 \mathrm{mM}$ apparently enhanced GSIS, glucose uptake, and ATP production, while at $25 \mathrm{mM}$ it notably decreased these three outcomes. Geniposide time-dependently induced phosphorylation of acetyl-CoA carboxylase, a marker of AMP-activated protein kinase (AMPK) activity, and this effect was notably inhibited by compound C, a selective AMPK inhibitor. Additionally, the knockdown of AMPK protein with AMPK small interfering RNA (siRNA) treatment attenuated geniposide-regulated GSIS, glucose uptake, and ATP production, suggesting that AMPK plays an essential role in the regulatory effect of geniposide on GSIS [18]. In the presence of low $(5.5 \mathrm{mM})$ or moderately high (11 $\mathrm{mM}$ ) levels of glucose, geniposide at $10 \mu \mathrm{M}$ enhanced GSIS, glucose uptake, and intracellular ATP level. However, it also exerted a contrary role in the presence of a high $(33 \mu \mathrm{M})$ level of glucose. Furthermore, geniposide ameliorated the impairment of GSIS stimulated by glucose $(33 \mu \mathrm{M})$ [19].

Regulation of proteasome-dependent thioredoxininteracting protein degradation may be a novel strategy to prevent the glucotoxicity in pancreatic $\beta$-cells. Geniposide accelerated the degradation of thioredoxin-interacting protein via proteasome pathway in high-glucose- $(25 \mathrm{mM})$ treated INS-1 cells. Moreover, geniposide obviously inhibited MG132- (a proteasomal inhibitor) induced enhancement of GSIS, glucose uptake, and metabolism [20]. In another study, it induced insulin secretion, phosphorylation of Akt473 and phosphoinositide-dependent protein kinase 1, and the expression of glucose transporter 2. Furthermore, it decreased the phosphorylation of downstream target GSK-3 $\beta$, and this effect was reversed by LY294002 $(10 \mu \mathrm{M})$ [21]. The glucagon-like-1 receptor (GLP-1R) antagonist exendin (9-39) (200 nM) or knockdown of GLP-1R gene with short hairpin RNA interference offsets the effect of geniposide on insulin secretion stimulated by glucose (5.5 mM) [22]. Moreover, geniposide modulated pyruvate carboxylase expression and the production of intermediates of glucose metabolism [19]. In rat pancreatic islets, geniposide facilitated insulin secretion by activating GLP-1R and the adenylyl cyclase/cAMP signaling pathway, and this effect was blocked via inhibition of PKA. Moreover, geniposide suppressed voltage-dependent potassium channels, and this effect was alleviated via inhibition of GLP-1R or PKA. Furthermore, it prolonged action potential duration and activated $\mathrm{Ca}^{2+}$ channels [23].

$\beta$-cell apoptosis is considered to be a major cause of loss of $\beta$ cells in diabetes. Geniposide significantly inhibited high-glucose- $(25 \mathrm{mM})$ induced cell damage in INS1 cell. Consistently, it upregulated the protein levels of cell apoptosis-associated enzymes, including heme oxygenase-1 (HO-1) and Bcl-2, while decreasing the protein level of Bax, and these effects were reversed by compound C, but were potentiated by AICAR, an AMPK activator. Furthermore, high glucose-induced cleavage of caspase-3 was prevented by geniposide, and this effect was inhibited by compound C. Additionally, the effects of geniposide on the apoptosisassociated proteins and cell viability were attenuated by AMPK siRNA [24]. Incubation with geniposide at $20 \mu \mathrm{M}$ for 3 days promoted $\beta$-cell survival through accelerating $\beta$ cell proliferation and inhibiting $\beta$-cell apoptosis in cultured mouse islets after treatment with diabetic stimuli. Geniposide protected $\beta$-cell by activating Wnt signaling and Akt, promoting expressions of T-cell factor 7-like 2 (TCF7L2) and GLP$1 \mathrm{R}$, suppressing GSK-3 $\beta$ activity, and increasing $\beta$-catenin nuclear translocation, and this effect was obviously reversed by siRNAs against $\beta$-catenin or by ICG001 ( $\beta$-catenin/TCFmediated transcription inhibitor). Intragastric administration of geniposide at $100 \mathrm{mg} / \mathrm{kg}$ promoted $\beta$-cell regeneration to normalize blood glucose in high-fat diet and $\mathrm{db} / \mathrm{db}$ mice. In exocrine cells isolated from mouse pancreas, it induced duct cell differentiation by increasing TCF7L2 expression and activating Janus kinase 2/STAT3 pathway [25]. In INS-1 cells, pretreatment with geniposide for $7 \mathrm{~h}$ decreased palmitateinduced $\beta$-cell apoptosis and active caspase- 3 expression, and this effect was reversed by exendin (9-39). Additionally, geniposide ameliorated palmitate-stimulated impairment of GLP-1R signaling by increasing the phosphorylation of Akt and FoxO1 and elevating the expression of pancreatic and duodenal homeobox 1 [26].

Islet amyloid deposition is increasingly seen as a pathogenic feature of type 2 diabetes mellitus, with the deposits containing the unique amyloidogenic peptide islet amyloid polypeptide (IAPP, also known as amylin). Preincubation with geniposide prevented human IAPP- (hIAPP-) induced cell damage in INS-1E cells, and this effect was significantly inhibited by bacitracin, an inhibitor of IDE activity. In addition, it induced the expression of IDE, a key degrading protein of hIAPP, but had no obvious effect on the aggregation of hIAPP, suggesting that geniposide prevents hIAPP-induced cytotoxicity in INS-1E cells via upregulation of IDE expression [27]. In STZ-induced diabetic rats, geniposide at 12.5 and 
$25 \mathrm{mg} / \mathrm{kg}$ reduced the level of $\mathrm{A} \beta_{1-42}$ in the hippocampus and at $12.5 \mathrm{mg} / \mathrm{kg}$, it apparently inhibited STZ-induced reduction of the expression of IDE in the hippocampus [10]. Intragastric administration of geniposide at 5, 10, and $20 \mathrm{mg} / \mathrm{kg}$ for 4 weeks significantly reduced the levels of cerebral $\mathrm{A} \beta$ peptides $\left(\mathrm{A} \beta_{1-40}\right.$ and $\left.\mathrm{A} \beta_{1-42}\right)$ in APP/PS1 transgenic mice treated with STZ. Moreover, geniposide lowered the protein levels of ADAM10 (associated with $\alpha$-secretase) and increased the expression of $\beta$-site APP-cleaving enzyme (BACE1, associated with $\beta$-secretase) and IDE both in STZ-treated AD mice and in primary cultured cortical neurons. Geniposide at 10 $\mu \mathrm{M}$ augmented the effect of insulin via decreasing $\mathrm{A} \beta_{1-42}$ level in primary cultured cortical neurons [28].

Furthermore, intragastric administration of geniposide at $25 \mathrm{mg} / \mathrm{kg}$ for 46 days significantly lowered the level of blood glucose, total cholesterol, and triglyceride, while elevating blood insulin levels in STZ-induced diabetic rats [10]. Treatment with geniposide at 200 and $400 \mathrm{mg} / \mathrm{kg}$ for 2 weeks reduced the blood glucose, insulin, and triglyceride levels in type 2 diabetic mice induced by a high-fat diet and STZ injection in a dose-dependent manner. Moreover, the expression of hepatic glycogen phosphorylase and glucose6-phosphatase at mRNA and immunoreactive protein levels, as well as enzyme activity, was decreased in these mice [29]. Geniposide dose-dependently suppressed hepatic glucose production in HepG2 cells and different concentrations of this bioactive compound stimulated AMPK, acetyl coenzyme A synthetase and FoxO1 phosphorylation, and inhibited the activities of phosphoenolpyruvate carboxykinase and glucose-6-phosphatase. These effects were partially counteracted by suppression of AMPK activity via compound C and by inhibition of AMPK $\alpha$ expression via siRNA, suggesting that geniposide potentially ameliorates hyperglycemia involving inhibition of hepatic gluconeogenesis via modulation of the AMPK-FoxO1 signaling pathway [30].

In spontaneously obese type 2 diabetic mice, geniposide suppressed body weight and visceral fat accumulation, alleviated abnormal lipid metabolism and intrahepatic lipid accumulation, and ameliorated abnormal glucose tolerance and hyperinsulinemia, suggesting that it has an insulin resistance-alleviating effect [31]. Furthermore, it significantly ameliorated renal function by decreasing levels of serum creatinine, blood urea nitrogen, urinary albumin and elevator renal index and attenuating glomerular basement membrane in STZ-induced diabetic rats. Furthermore, geniposide inhibited monocytes and T-cell infiltration and reduced production of intercellular cell adhesion molecule-1, TNF- $\alpha$, IL-1, and IL-6. Additionally, it suppressed the activation of NF- $\kappa \mathrm{B}$ by decreasing expression of NF- $\kappa \mathrm{B}$ p 65 , IKK $\alpha$, and p-I $\kappa \mathrm{B}-\alpha$ in renal tissue, indicating that it is able to ameliorate structural and functional abnormalities of kidney in diabetic rats [32]. Geniposide at 10-20 $\mu \mathrm{M}$ suppressed adhesion of monocytes to human umbilical vein endothelial cells (HUVECs) stimulated by high glucose $(33 \mathrm{mM})$ in a concentration-dependent manner. At a concentration of 5-40 $\mu \mathrm{M}$, it lowered highglucose-stimulated gene and protein expression of vascular cell adhesion molecule 1 and E-selectin. At a concentration of 5-20 $\mu \mathrm{M}$, it inhibited ROS production and blocked I $\kappa \mathrm{B}$ degradation in the cytoplasm and NF- $\kappa \mathrm{B}$ translocation from the cytoplasm to the nucleus in HUVECs, suggesting that geniposide may have a role in the treatment for diabetic vascular injury [33].

2.3. Anti-Parkinson's Disease Activity. PD is a noncurable chronic neurodegenerative disease at present and geniposide has shown neuroprotective effects in PD models in several in vivo and in vitro studies. In four 1-methyl-4-phenyl-1,2,3,6tetrahydropyridine- (MPTP-) $(30 \mathrm{mg} / \mathrm{kg}$, i.p.) induced acute PD model mice, intraperitoneal injection of geniposide at 100 $\mathrm{mg} / \mathrm{kg}$ for 8 days ameliorated bradykinesia and movement balance and improved locomotor and exploratory activity. In addition, MPTP treatment reduced tyrosine hydroxylase positive neuron, lessened the level of $\mathrm{Bcl}-2$, and increased the level of $\mathrm{Bax}$, the ratio of $\mathrm{Bax} / \mathrm{Bcl}-2$, and the activation of caspase- 3 in the substantia nigra. Nevertheless, these alterations were reversed by geniposide, suggesting that the neuroprotective activity of geniposide is associated with upregulation of growth factor signaling and reduction of apoptosis [34]. In human neuroblastoma SH-SY5Y cells treated with $\mathrm{N}$-methyl-4-phenylpyridinium iodide in vitro and PD model mice induced by MPTP $(20 \mathrm{mg} / \mathrm{kg})$ in vivo, geniposide administration decreased microRNA-21 (miR-21) level, increased lysosome-associated membrane protein $2 \mathrm{~A}$ (LAMP-2A) level, and lessened $\alpha$-synuclein protein expression. LAMP-2A mediated the regulation of $\alpha$-synuclein by miR-21. The high expression of LAMP-2A retarded the upregulation of $\alpha$-synuclein induced by miR-21 mimic. The downregulating effect of geniposide on $\alpha$-synuclein was reversed by miR-21 mimics/agomir, while it was augmented by miR-21 inhibitor, suggesting that geniposide exerts its neuroprotective effects through reducing $\alpha$-synuclein expression via the miR-21/LAMP-2A axis in PD models [35].

2.4. Inhibition of Ischemia and Reperfusion Injury. The protective effect of geniposide against ischemic brain injury has been investigated in in vitro and in vivo models and increasing number of studies have focused on its therapeutic role in ischemic cerebral disease. Oral administration of geniposide at $50 \mathrm{mg} / \mathrm{kg}$ for 30 days exhibited an improved effect on learning and memory ability and neural protective effects in chronic cerebral ischemia model rats induced by permanent occlusion of bilateral common carotid arteries [36]. Geniposide at $75 \mathrm{mg} / \mathrm{kg}$ regulated antiapoptotic functions and suppressed blood-brain barrier leakage/haemorrhage by increasing GluN2A-containing $N$-methyl-D-aspartate receptor expression in transient middle cerebral artery occlusion rats, and these effects could be counteracted by GluN2A antagonist NVP-AAM077, but not the GluN2B inhibitor ifenprodil. Furthermore, the protective effect of geniposide was attributed to the upregulation of GluN2A-dependent survival signals, including p-Akt, p-ERK, and postsynaptic density protein- 95 , suggesting that it protects neurons against postischaemic neurovascular injury involving activation of GluN2A/Akt/ERK pathways [37]. Preadministration of geniposide at 5,10 , and $20 \mathrm{mg} / \mathrm{kg}$ protected Sprague-Dawley rats against hepatic ischemia/reperfusion injury by decreasing alanine transaminase (ALT), aspartate transaminase (AST), lactate dehydrogenase, Bax, IL-6, monocyte chemotactic 
protein 1 , and TNF- $\alpha$ levels, increasing Bcl-2, PI3K, p-Akt, and mammalian target of rapamycin (mTOR) expressions, and lowering inflammatory cell infiltration, cellular swelling, and vacuolar degeneration [38].

Furthermore, treatment with geniposide at 15, 30, and $60 \mathrm{mg} / \mathrm{kg}$ through tail vein injection lowered the infarct volume and suppressed the activation of microglial cells in ischemic penumbra of ischemia/reperfusion-injured rats induced by middle cerebral artery occlusion. In oxygenglucose deprivation- (OGD-) treated rat microglial cells, geniposide at $12.5,25$, and $50 \mu \mathrm{g} / \mathrm{mL}$ restrained the increase of cell viability and release of TNF- $\alpha$, IL- $1 \beta$, IL-6, IL- 8 , and IL10. Furthermore, it lowered OGD-induced increase of Tolllike receptor 4 (TLR4) mRNA and protein levels. Geniposide at 25 and $50 \mu \mathrm{g} / \mathrm{mL}$ attenuated the phosphorylation of ERK, I $\kappa \mathrm{B}$, and $\mathrm{p} 38$ and suppressed nuclear transcriptional activity triggered via NF- $\kappa \mathrm{B}$ p 65 [39]. Additionally, it significantly suppressed the upregulated mRNA and protein expression of $\mathrm{P}_{2} \mathrm{Y}_{14}$ and inhibited the phosphorylation of Raf-1, mitogen-activated protein kinase kinase 1/2 (MEK1/2), and ERK1/2 both in OGD-induced rat brain microvascular endothelial cells (BMECs) and in UDP-glucose stimulated BMECs. Moreover, it notably reduced the production of IL8 , IL- $1 \beta$, and monocyte chemotactic protein 1 in BMECs treated with OGD [40]. In rat hippocampal slice culture, it attenuated OGD-induced neuronal cell death. Besides, geniposide exhibited a greater protective effect on the granule cell layer than on the pyramidal cell layer including CA 1 and CA 3 region in the hippocampus [41]. In addition, it increased the viability of neonate rat primary cortical neuron with sodium dithionite-induced OGD/reperfusion [42].

In $\mathrm{H} 9 \mathrm{c} 2$ cells, pretreatment with geniposide in gradient concentrations of $2.5,5,10,20,40,80,160$, and $320 \mu \mathrm{M}$ for $30 \mathrm{~min}$ elevated cell viability, lowered lactate dehydrogenase levels, and suppressed cardiomyocyte apoptosis induced by hypoxia/reoxygenation. Furthermore, it lessened oxidative stress products (ROS/reactive nitrogen species and malondialdehyde), elevated antioxidative enzyme (total SOD) level, improved mitochondrial morphology, and inhibited mitochondrial calcium overload and depolarization of mitochondrial membrane, thus reversing mitochondrial dysfunction. Moreover, geniposide upregulated Bcl-2 and p$\mathrm{Akt}^{\text {serine } 473}$ levels, downregulated Bax level, caspase- 3 mRNA expression, and the protein expression of cleaved caspase3 and cytochrome-c, and these effects were partially counteracted by exendin (9-39) or LY294002, suggesting that it inhibits hypoxia/reoxygenation-induced myocardial apoptosis through reversing mitochondrial dysfunction, an effect in part due to activation of GLP-1R and PI3K/Akt signaling pathway [43].

2.5. Hepatoprotective Activity. Geniposide modified abnormal metabolism induced by ethanol exposure by alleviating disorders relating to amino acid metabolism and the oxidative stress state in alcohol-induced liver injury model mice [44]. Intragastric administration of geniposide at 20,40, and $80 \mathrm{mg} / \mathrm{kg}$ notably inhibited the acute alcohol-induced increase of both serum ALT/AST and hepatic lipid peroxidation levels. Furthermore, it increased the hepatic GSH, GSH transferase, GSH-Px, CuZn-SOD, and catalase (CAT) levels. Moreover, geniposide increased hepatic mRNA expressions of $\mathrm{CuZn-SOD}$ and CAT, indicating that it protects against acute alcohol-induced liver injury by upregulating the expression of the main antioxidant enzymes and thus improved alcohol-induced oxidative stress injury in the liver [45]. Treatment with geniposide at 25, 50, and $100 \mathrm{mg} / \mathrm{kg}$ for 6 weeks ameliorated liver histology by decreasing the elevated liver index (liver weight/body weight); serum ALT and AST in high-fat diet caused nonalcoholic steatohepatitis in model rats. Geniposide reduced total cholesterol, triglycerides, and free fatty acids in serum and liver. Additionally, it inhibited cytochromes P450 2E1 expression and elevated PPAR $\alpha$ expression [46].

In Sprague-Dawley rats, intragastric administration of geniposide at 25,50 , and $100 \mathrm{mg} / \mathrm{kg}$ blocked $\alpha$-naphthylisothiocyanate- (ANIT-) induced changes in serum markers for liver injury. Moreover, geniposide decreased basolateral bile acids uptake by repressing organic anion transporting polypeptide 2 . Furthermore, it markedly elevated canalicular bile acids secretion via bile acids export pump, subsequently stimulating bile flow during cholestasis. Meanwhile, geniposide significantly increased mRNA levels of organic solute transporter $\beta$. In addition, farnesoid $\mathrm{X}$ receptor, pregnane $\mathrm{X}$ receptor, and small heterodimer partner were activated, indicating the attenuation of ANIT-induced hepatotoxicity and cholestasis in rat via regulation of enzymes and transporters responsible for bile acids homeostasis [47]. In ICR mice, treatment with geniposide at $50 \mathrm{mg} / \mathrm{kg}$ for 5 days mitigated ANIT-induced cholestasis and liver injury. Furthermore, it normalized the altered gene transcription related to bile acid metabolism and transport and suppressed the activation and expression of STAT3 [48].

Pretreatment of mice with geniposide at 20,40, and $80 \mathrm{mg} / \mathrm{kg}$ for 7 days by intragastrical administration attenuated Tripterygium glycosides- $(270 \mathrm{mg} / \mathrm{kg})$ induced elevation of serum ALT/AST, hepatic malondialdehyde, and proinflammatory cytokine TNF- $\alpha$ level. Moreover, it increased Tripterygium glycosides-induced downregulation of biomarkers, including hepatic GSH level; activities of GSH transferase, GSH-Px, SOD and CAT, and anti-inflammatory cytokine IL-10 were observed. In addition, it promoted the mRNA expression of hepatic transforming growth factorbetal (TGF- $\beta 1$ ) [49]. In human HepG2 hepatocytes, geniposide suppressed palmitate-induced ER stress and inhibited hepatic lipid accumulation via secretion of apolipoprotein $\mathrm{B}$ and associated triglycerides and cholesterol. Moreover, lysosomal enzyme activities including V-ATPase were significantly increased, and these effects were reversed by bafilomycin, a V-ATPase inhibitor, suggesting that geniposide enhances lysosomal activity, resulting in reduction of ER stress and hepatic dyslipidemia [50]. Besides, it inhibited palmitate-induced cell death via enhancement of lysosome activity [51]. In AML12 cells, geniposide apparently blocked TGF- $\beta 1$-induced mRNA and protein expression of type-I collagen and phosphorylation of Smad2/3; ERK and Akt were significantly repressed [52]. Taken together, geniposide might be a potential therapeutic candidate for treatment of liver diseases. 
2.6. Anti-Inflammatory Activity. Geniposide is reported to relieve the secondary hind paw swelling and arthritis index and reduce phosphorylated c-Jun N-terminal kinase (JNK) expression and $\mathrm{T}$ helper 17 cell cytokines, while increasing regulatory $\mathrm{T}$-cell cytokines in mesenteric lymph node lymphocytes (MLNL) and peripheral blood lymphocytes of adjuvant arthritis rats [53]. Oral administration of geniposide at 30,60 , and $120 \mathrm{mg} / \mathrm{kg}$ attenuated histopathologic changes, decreased IL-2 level, and increased the level of IL-4 and TGF- $\beta 1$ in MLNL. Moreover, it elevated the expression of $\beta 2$-adrenergic receptor and lowered the expression of $\mathrm{G}$ protein-coupled receptor kinase $2, \beta$-arrestin- 1 and $\beta$ arrestin-2, and level of cyclic adenosine monophosphate of MLNL [54]. Furthermore, it facilitated the recovery of arthritis and suppressed the colonic inflammation damage through reducing the expression level of TNF- $\alpha$, IL-1, and IL-6, elevating the production of IL-10 and blocking the expression of phospho-p38 related proteins in fibroblastlike synoviocyte (FLS) [55]. In collagen-induced arthritis rat, oral administration of geniposide at 33, 66, and $132 \mathrm{mg} / \mathrm{kg}$ attenuated histopathologic changes of MLN and decreased the level of IL- 6 and IL-17, while the levels of IL-4 and TGF- $\beta 1$ in MLNL were increased. Additionally, geniposide promoted the proliferation capability of MLNL and inhibited the expressions of $\mathrm{p}$-Raf, $\mathrm{p}-\mathrm{MEK}$, and $\mathrm{p}$-ERK1/2 in MLNL [56], and these results might highlight the anti-inflammatory effect and possible mechanisms of geniposide in MLNL and FSL of rheumatoid arthritis.

In LPS-induced mastitis model mice, intraperitoneal administration of geniposide at $2.5,5$, and $10 \mathrm{mg} / \mathrm{kg}$ notably attenuated the infiltration of inflammatory cells. Besides, it decreased the expression of TNF- $\alpha$, IL- $1 \beta$, and IL- 6 both in LPS-induced mastitis model mice $(2.5,5$, and $10 \mathrm{mg} / \mathrm{kg})$ and in LPS-stimulated primary mouse mammary epithelial cells $(25,50$, and $100 \mu \mathrm{g} / \mathrm{mL})$. In addition, it inhibited the phosphorylation of $\mathrm{I} \kappa \mathrm{B}-\alpha, \mathrm{NF}-\kappa \mathrm{B}, \mathrm{p} 38, \mathrm{ERK}$, and JNK and the expression of TLR4, indicating that geniposide inhibits inflammation through regulating TLR4 expression, resulting in affection of the downstream NF- $\kappa \mathrm{B}$ and mitogen-activated protein kinase (MAPK) signaling pathways [57]. In C57BL/6 mice after Helicobacter pylori infection, geniposide inhibited vacuolating cytotoxin A gene expression, downregulated the serum levels of IFN- $\gamma$, IL- $1 \beta$, and immunoglobulins $A$ and $\mathrm{M}$ and decreased the inflammatory maker cyclooxygenase 2 (COX-2) [58]. Furthermore, it notably inhibited proinflammatory cytokines through regulating NF- $\kappa \mathrm{B}$ and PPAR $\gamma$ pathways in dextran sulfate sodium-induced experimental colitis in mice and LPS-triggered inflammation in Caco-2 cells. Besides, geniposide notably regulated the expressions of zonula occludens-1 and occludin attenuated body weight loss, disease activity index, colon length shortening, and colonic pathological damage in dextran sulfate sodiuminduced colitis model mice [59].

In another study, administration of geniposide at 25 and $50 \mathrm{mg} / \mathrm{kg}$ notably elevated the decreased body weight and improved experimental colitis and related symptoms in 2,4,6trinitrobenzene sulfonic acid-induced experimental ulcerative colitis model rats. Geniposide inhibited inflammatory cytokine release, including TNF- $\alpha$, IL-1 $\beta$, and IL-6, and neutrophil infiltration (myeloperoxidase activity) in the colon. At a concentration of $25-100 \mu \mathrm{g} / \mathrm{mL}$, geniposide improved LPS-induced endothelial barrier dysfunction via the dose-dependent upregulation of transepithelial electrical resistance in Caco- 2 cells. Furthermore, it lowered the protein expression of NF- $\kappa \mathrm{B}, \mathrm{COX}-2$, inducible nitric oxide synthase (iNOS), and myosin light-chain kinase (MLCK), increased the expression of tight junction proteins (occludin and zonula occludens-1), and accelerated AMPK phosphorylation both in vivo and in vitro. Geniposide-reduced MLCK protein expression was antagonized by both AMPK siRNA transfection and AMPK overexpression, suggesting that geniposide improves barrier dysfunction via AMPK-mediated inhibition of the MLCK pathway. Taken together, geniposide improved 2,4,6-trinitrobenzene sulfonic acid-induced colitis by attenuating inflammation and regulating the disrupted epithelial barrier function via activating the AMPK signaling pathway [60]. Moreover, it alleviated inflammation in acute liver injury model mice and in LPS-stimulated THP-1 cells. Geniposide decreased the expressions of Methyl-CpG binding protein 2, Sonic hedgehog, and GLIS family zinc finger 1, while elevating Patched1 expression, suggesting that it may be an effective modulator of Methyl-CpG binding protein 2-hedgehog pathway during the pathogenesis of inflammation [61]. Pretreatment with geniposide at 20, 40, and $80 \mathrm{mg} / \mathrm{kg}$ reduced inflammatory cells and total protein concentration in the bronchoalveolar lavage fluid of LPSinduced acute lung injury model mice and furthermore reduced levels of inflammatory mediators, including TNF- $\alpha$, IL-6, IL-10 [62], and IL-1 $\beta$ were observed [63]. In addition, it suppressed LPS-induced alveolar wall changes, alveolar haemorrhage, and neutrophil infiltration in lung tissue by reducing myeloperoxidase activity [62].

In primary mouse macrophages, geniposide significantly suppressed the expression of TLR4 and the production of TNF- $\alpha$, IL- 6 , and IL- $1 \beta$ induced by LPS and prevented LPSinduced phosphorylation of $\mathrm{I} \kappa \mathrm{B}-\alpha$, p65, p38, ERK, and JNK. Moreover, it inhibited the LPS-induced IL- 8 production in mTLR4 and mMD-2 cotransfected HEK293 cells [63]. In murine microglial N9 cells, pretreatment with geniposide at 40,80 , and $160 \mu \mathrm{g} / \mathrm{mL}$ for $20 \mathrm{~h}$ suppressed the activation of cells and restrained the overproduction of NO, intracellular ROS, and the expression of iNOS induced by LPS $(1 \mu \mathrm{g} / \mathrm{mL})$. Geniposide at 80 and $160 \mu \mathrm{g} / \mathrm{mL}$ inhibited LPS-induced drop-off of $\mathrm{I} \kappa \mathrm{B}$ and phosphorylation of p38 and ERK1/2 [64]. In murine macrophage RAW 264.7 cells, it decreased the expression of TNF- $\alpha$, IL-1, IL-6, and IL- $1 \beta$ and furthermore suppressed activation of NF$\kappa \mathrm{B}$ and expression of TLR4 at both mRNA and protein levels $[65,66]$. Pretreatment with geniposide at 40, 80, and $160 \mu \mathrm{g} / \mathrm{mL}$ for $1 \mathrm{~h}$ dose-dependently exerted antiinflammatory effects through preventing the LPS-stimulated $\mathrm{NF}-\kappa \mathrm{B}, \mathrm{MAPK}$, and activator protein-1 signaling pathway activation, subsequently blocking the overexpression of the inducible enzymes iNOS and COX-2. Furthermore, geniposide inhibited the expression and release of inflammatoryassociated mediators TNF- $\alpha$, IL- 6 , prostaglandin $\mathrm{E}_{2}$, and NO [67]. In HUVECs, treatment with geniposide at $25-100 \mu \mathrm{g} / \mathrm{mL}$ for $24 \mathrm{~h}$ evidently decreased LPS-induced transcription 
and translation levels of IL- 6 and IL- 8 and blocked LPSinduced HUVEC migration and U937 monocyte adhesion to HUVECs. Moreover, geniposide inhibited the activation of NF- $\kappa \mathrm{B}$, degradation of $\mathrm{I} \kappa \mathrm{B}-\alpha$, and phosphorylation of p38 MAPK and ERK1/2 in HUVECs stimulated by LPS, indicating that it attenuates LPS-stimulated IL-6 and IL-8 production in HUVECs through inhibiting p38 MAPK and ERK1/2 signaling pathways [68]. In summary, geniposide has the potential to be a therapeutic agent in the treatment of inflammatory diseases, including mastitis, colitis, and arthritis.

2.7. Antidepressant-Like Activity. Treatment with geniposide at 25,50 , and $100 \mathrm{mg} / \mathrm{kg}$ counteracted chronic unpredictable mild stress-induced behavioral abnormalities by increasing sucrose intake, improving crossing and rearing behavior in open field test, and by shortening immobility and prolonging swimming time in forced swimming test. Moreover, geniposide ameliorated chronic unpredictable mild stressinduced hyperactivity of hypothalamus-pituitary-adrenal axis through reducing corticosterone serum level, adrenal gland index, and hypothalamic corticotrophin-releasing hormone mRNA expression. Additionally, it increased the expression of hypothalamic glucocorticoid receptor $\alpha$ at both mRNA and protein levels in paraventricular nucleus, suggesting that geniposide ameliorates the impaired glucocorticoid receptor $\alpha$ negative feedback on corticotrophinreleasing hormone expression and hypothalamus-pituitaryadrenal axis and indicating that the therapeutic effects of geniposide are essentially similar to fluoxetine [69]. In STZinduced diabetic mice, intragastric administration of geniposide at 50 and $100 \mathrm{mg} / \mathrm{kg}$ alleviated the elevated blood sugar and immobility time in forced swimming test. Furthermore, it upregulated brain-derived neurotrophic factor levels and increased the mRNA expression of brain-derived neurotrophic factor and tropomyosin-related kinase B in hippocampus of diabetic mice, indicating that geniposide alleviates depression-like behavior in STZ-induced diabetic mice and suggesting that its mechanisms may partially be associated with upregulating brain-derived neurotrophic factor expression in brain [70].

2.8. Antioxidant Activity. In primary cultured hippocampal neurons, pretreatment with geniposide increased the HO-1 expression and subsequently inhibited cell apoptosis stimulated by 3-morpholinosydnonimine hydrochloride (SIN$1,1 \mathrm{mM})$. Additionally, geniposide $(10 \mu \mathrm{M})$ enhanced the nuclear translocation of nuclear factor-E2-related factor 2 and activation of PI3K in the presence of SIN-1-induced oxidative stress, and these effects could be retarded by LY294002 $(10 \mu \mathrm{M})$ and Zinc protoporphyrin (an inhibitor of HO-1, $10 \mu \mathrm{M})$, indicating that it protects primary hippocampal neurons from oxidative stress by regulating nuclear factorE2-related factor 2 translocation and downstream antioxidant protein HO-1 expression via PI3K/Akt signaling pathway [71]. In another study, geniposide-induced luciferase activity enhanced after transfecting PC12 cells with the AB1 enhancer from the HO-1 gene, but not in the PC12 cells whose GLP$1 \mathrm{R}$ gene was disrupted. Moreover, the neuroprotective activity of geniposide in PC12 cells was blocked by the prevention of HO-1 activity via Sn-protoporphyrin IX or short hairpin RNA-mediated knockdown of GLP-1R, suggesting that GLP$1 \mathrm{R}$ plays a critical role in geniposide-induced $\mathrm{HO}-1$ expression to attenuate oxidative insults in PC12 cells [72].

2.9. Antiapoptotic Activity. Geniposide significantly reduced the percentage of sodium nitroprusside-stimulated chondrocytes in G0/G1 phase and elevated percentage in S phase and $\mathrm{G} 2 / \mathrm{M}$ phase in vitro. In addition, it suppressed the apoptosis of chondrocyte and the concentration of NO in the culture supernatants. Moreover, it impacted sodium nitroprussideinduced apoptosis of chondrocyte by reducing the concentration of NO and promoting proliferation of chondrocytes, and this effect was a probable and important mechanism of geniposide preventing osteoarthritis [73]. Intraperitoneal administration of geniposide at 2.5, 5, and $10 \mathrm{mg} / \mathrm{kg}$ inhibited mammary gland apoptosis, Bax expression, and the phosphorylation of caspase- 3 cleavage and p53 and augmented $\mathrm{Bcl}-2$ expression in LPS- $(0.2 \mathrm{mg} / \mathrm{mL})$ induced mastitis model mice. In LPS- $(1 \mu \mathrm{g} / \mathrm{mL})$ induced primary mouse mammary epithelial cells, geniposide at 25,50 , and $100 \mu \mathrm{g} / \mathrm{mL}$ downregulated the ratio of dead cells in a concentrationdependent manner. Consistently, geniposide attenuated the expressions of Bax and TLR4, caspase- 3 cleavage, and the phosphorylation of $\mathrm{p} 53$, while increasing $\mathrm{Bcl}-2$ expression, suggesting that the antiapoptotic property of geniposide is due to its modulation of TLR4 and apoptosis-related factors (p53, Bax, Bcl-2, and caspase-3) in LPS-induced mouse mastitis [74]. Additionally, it significantly ameliorated cell viability and morphology, reduced the expression of Bax, P53, and caspase-9, and upregulated the expression of Bcl-2 in $\mathrm{CoCl}_{2}$-stimulated PC12 cells [75].

2.10. Immune-Regulatory Activity. Oral administration of geniposide at $100 \mathrm{mg} / \mathrm{kg}$ for 12 weeks showed immuneregulatory effects and inhibited the formation of atherosclerotic lesions via lowering the dendritic cell numbers and prevented dendritic cell maturation in bone marrow and infiltration into lesions in ApoE-knockout mice [76]. Furthermore, it increased FoxP3 expression, elevated the number and function of regulatory $\mathrm{T}$ cells, and improved the atherosclerotic lesions progression partly via lipid regulation and immunoregulation in ApoE-/- mice fed a high-cholesterol diet [77].

2.11. Antisepsis Activity. In RAW264.7 cells, geniposide could directly bind and neutralize LPS and it dose-dependently blocked LPS-induced cytokines release, reduced the upregulated TNF- $\alpha$ and TLR4 mRNA expression, and inhibited the phosphorylation of p38 MAPK. In vivo, treatment with geniposide at $40 \mathrm{mg} / \mathrm{kg}$ protected mice challenged with lethal heat-killed Escherichia coli and downregulated the level of serum endotoxin in endotoxemia mice [78]. Geniposide exhibited high binding affinity for lipid A, the bioactive center of lipopolysaccharide (LPS). In LPS-induced sepsis model mice, geniposide lowered LPS levels and release of IL- 6 and TNF- $\alpha$ induced by LPS and exhibited protective activities on liver, heart, and lung [79]. 


\subsection{Other Biological Activities}

2.12.1. Cardioprotective Activity. Intragastric administration of geniposide at $50 \mathrm{mg} / \mathrm{kg}$ for 7 weeks inhibited cardiac hypertrophy induced by constriction of the transverse aorta or by isoprenaline in mice. It also activated AMPK $\alpha$ and decreased phosphorylated level of mTOR, ERK, and protein kinase double-stranded RNA-dependent-like ERK in hypertrophic heart induced by constriction of the transverse aorta. Furthermore, geniposide attenuated the expressions of glucose regulated protein $78, \mathrm{X}$-box binding protein 1 , and activating transcription factor 6 . GLP-1R blockade retarded the antihypertrophic response and activation of AMPK $\alpha$ by geniposide. Besides, knockdown of GLP-1R impeded the inhibitory effects of geniposide on cardiac hypertrophy in vivo, suggesting that it protects against cardiac hypertrophy via GLP-1R and AMPK $\alpha$ and indicating that it may be a potential therapeutic candidate for cardiac hypertrophy [80].

2.12.2. Antinociceptive Activity. Geniposide concentrationdependently exerted the protective effect against hydrogen peroxide-caused oxidative damage in PC12 and HEK293 cells expressing rat and human GLP-1R, but not in HEK293T cells that do not express GLP-1R. Oral and subcutaneous administration of geniposide dose-dependently inhibited formalininduced tonic response, but not the acute flinching response. Intrathecal administration of geniposide induced antinociception in a dose-dependent manner, and this effect was completely reversed by spinal exendin (9-39), siRNA/GLP$1 R$, and cyclic AMP/PKA pathway inhibitors, suggesting that geniposide exerts antinociception during persistent pain by activating the spinal GLP-1R [81].

2.12.3. Apoptotic Activity. In vitro, geniposide suppressed adjuvant-induced arthritis (AIA) FLS proliferation in a dosedependent manner and induced typical apoptotic morphological characteristics including nuclear shrinkage and chromatin condensation and notably promoted the apoptosis rate of AIA FLS. Furthermore, it reduced Bcl-2 mRNA level and elevated Bax and caspase- 3 mRNA levels and lowered protein level of phosphorylated-ERK1/2, indicating that geniposide induced AIA FLS apoptosis by regulating the apoptosisrelated gene expressions and preventing ERK signal pathway [82].

2.12.4. Antithrombotic Activity. Geniposide at $20 \mathrm{mg} / \mathrm{kg}$ suppressed thrombin/collagen-induced platelet aggregation with $52.8 \% / 26.2 \%$ aggregation rate in rats ex vivo. At a concentration of $10-40 \mathrm{mg} / \mathrm{kg}$, it inhibited venous thrombosis induced by tight ligation of the inferior vena cava in mice, and the $E D_{50}$ value was $18.4 \mathrm{mg} / \mathrm{kg}$ [83].

2.12.5. Antiviral Activity. Geniposide inhibited enterovirus 71 replication and viral internal ribosome entry site activity, suggesting that it may be a potential chemopreventive agent against enterovirus 71 infections [84].

2.12.6. Promelanogenesis Activity. In norepinephrine-treated normal human epidermal melanocyte, geniposide enhanced melanogenesis via stem cell factor/c-kit signalling in which the expression of c-kit receptor was increased [85].

2.12.7. Antitumoral Activity. Geniposide at 50 and $100 \mu \mathrm{M}$ was able to stabilize covalent attachments of the topoisomerase I subunits to DNA at sites of DNA strand breaks, generating cleavage complexes intermediates so being active as poisons of topoisomerase I, suggesting that DNA damage induced by topoisomerase I poisoning may be one of the possible mechanisms of antitumoral activity displayed by geniposide [86].

\section{Conclusion}

Geniposide, the major iridoid glycoside of Gardeniae Fructus, has been isolated from nearly 40 species of plants and most of which are used as traditional phytomedicines. Increasing body of pharmacological evidence has emerged for the multiple bioactive functions of geniposide, including neuroprotective, antidiabetic, hepatoprotective, antiinflammatory, analgesic, antidepressant-like, cardioprotective, antioxidant, immune-regulatory, antithrombotic, and antitumoral effects. The active mechanisms are related to enhancement of SOD, GSH, CAT, IDE, PPAR $\gamma$, and FoxO1, inhibition of ROS, NO, ALT, AST, and $\alpha$-synuclein, and regulation of signaling pathways such as AMPK, NF- $\kappa \mathrm{B}$, and PI3K/Akt. In vivo and in vitro studies showed that geniposide could pass through the blood-brain barrier with poor permeability $[87,88]$. However, the poor blood-brain barrier permeability of geniposide could be significantly improved via structural modification [89] or prescription with a messenger agent, such as borneol and muscone [88, 90]. Collectively, it has been suggested that geniposide may be a drug or lead compound for the prophylaxis and treatment of several diseases, such as $\mathrm{AD}, \mathrm{PD}$, diabetes and diabetic complications, ischemia and reperfusion injury, and hepatic disorders.

However, the study of geniposide is only in the primary stage since the molecular mechanisms and targets underlying pharmacological effects are not yet clearly defined. At present, its clinical application is mainly in the form of traditional Chinese preparations instead of geniposide monomer. In addition, toxicity of geniposide has also been reported, for example, hepatotoxicity [91, 92]; oral chronic toxicity of geniposide in rats has also been reported which resulted in the serum biochemistry, urinalysis, haematological parameters, and relative organ weights being affected. Furthermore, its usage has caused noticeable pathological abnormalities in liver and kidney tissues [93]. Besides, it shows two-way regulation on certain effects, which may be related to the dosage and experimental subjects, but the specific reasons are not very clear. Thus, further studies are required to verify and develop the safe use of geniposide.

\section{Conflicts of Interest}

The authors have declared that there are no conflicts of interests. 


\section{Authors' Contributions}

Yan-Xi Zhou and Ruo-Qi Zhang contributed equally to this work.

\section{Acknowledgments}

This work was supported by funds from Chengdu University of Traditional Chinese Medicine (ZRQN1655 and YXRC2018006).

\section{References}

[1] M. Shan, S. Yu, H. Yan et al., "A Review on the phytochemistry, pharmacology, pharmacokinetics and toxicology of geniposide, a natural product," Molecules, vol. 22, no. 10, E1689, 2017.

[2] W. Liu, G. Li, C. Hölscher, and L. Li, "Neuroprotective effects of geniposide on Alzheimer's disease pathology," Reviews in the Neurosciences, vol. 26, no. 4, pp. 371-383, 2015.

[3] P. Sun, J. Y. Chen, J. Li et al., "The protective effect of geniposide on human neuroblastoma cells in the presence of formaldehyde," BMC Complementary and Alternative Medicine, vol. 13, no. 152, 2013.

[4] J. Chen, M. Sun, X. Wang et al., "The herbal compound geniposide rescues formaldehyde-induced apoptosis in N2a neuroblastoma cells," Science China Life Sciences, vol. 57, no. 4, pp. 412-421, 2014.

[5] P. Sun, H. Ding, M. Liang et al., "Neuroprotective effects of geniposide in SH-SY5Y cells and primary hippocampal neurons exposed to A $\beta 42$," BioMed Research International, vol. 2014, Article ID 284314, 11 pages, 2014.

[6] F. Yin, Y. Zhang, L. Guo, S. Kong, and J. Liu, "Geniposide regulates insulin-degrading enzyme expression to inhibit the cytotoxicity of A $\beta 1-42$ in cortical neurons," CNS and Neurological Disorders - Drug Targets, vol. 11, no. 8, pp. 1045-1051, 2012.

[7] C. Lv, L. Wang, X. Liu et al., "Geniposide attenuates oligomeric A $\beta(1-42)$-induced inflammatory response by targeting RAGEdependent signaling in BV2 cells," Current Alzheimer Research, vol. 11, no. 5, pp. 430-440, 2014.

[8] C. Lv, L. Wang, X. Liu et al., "Multi-faced neuroprotective effects of geniposide depending on the RAGE-mediated signaling in an Alzheimer mouse model," Neuropharmacology, vol. 89, pp. 175184, 2015.

[9] Y. Zhang, Z. Xia, J. Liu, and F. Yin, "Geniposide attenuates oligomeric $\mathrm{A} \beta(1-42)$-induced inflammatory response by targeting RAGE-dependent signaling in BV2 cells," CNS \& Neurological Disorders-Drug Targets, vol. 14, no. 3, pp. 370-377, 2015.

[10] J. Liu, Y. Zhang, X. Deng, and F. Yin, “Geniposide decreases the level of $\mathrm{A} \beta 1-42$ in the hippocampus of streptozotocin-induced diabetic rats," Acta Biochimica et Biophysica Sinica, vol. 45, no. 9, pp. 787-791, 2013.

[11] Z. Liu, Y. Zhang, J. Liu, and F. Yin, "Geniposide attenuates the level of $A \beta 1-42$ via enhancing leptin signaling in cellular and APP/PS1 transgenic mice," Archives of Pharmacal Research, vol. 40, no. 5, pp. 571-578, 2017.

[12] J. Liu, Z. Liu, Y. Zhang, and F. Yin, "Leptin signaling plays a critical role in the geniposide-induced decrease of tau phosphorylation," Acta Biochimica et Biophysica Sinica, vol. 47, no. 12, pp. 1018-1022, 2015.
[13] Y. Zhang, F. Yin, J. Liu, and Z. Liu, "Geniposide attenuates the phosphorylation of tau protein in cellular and insulindeficient APP/PS1 transgenic mouse model of Alzheimer's disease," Chemical Biology \& Drug Design, vol. 87, no. 3, pp. 409418, 2016.

[14] C. Gao, Y. Liu, Y. Jiang, J. Ding, and L. Li, "Geniposide ameliorates learning memory deficits, reduces tau phosphorylation and decreases apoptosis via GSK3 $\beta$ Pathway in streptozotocininduced alzheimer rat model," Brain Pathology, vol. 24, no. 3, pp. 261-269, 2014.

[15] C. Zhao, C. Lv, H. Li et al., "Geniposide protects primary cortical neurons against oligomeric $\mathrm{A} \beta 1$-42-induced neurotoxicity through a mitochondrial pathway," PLoS ONE, vol. 11, no. 4, Article ID e0152551, 2016.

[16] C. Lv, X. Liu, Z. Li, H. Liu, T. Chen, and W. Zhang, "Geniposide attenuates mitochondrial dysfunction and memory deficits in APP/PS1 transgenic mice," Current Alzheimer Research, vol. 11, no. 6, pp. 580-587, 2014.

[17] J.-H. Liu, F. Yin, L.-X. Guo, X.-H. Deng, and Y.-H. Hu, “Neuroprotection of geniposide against hydrogen peroxide induced PC12 cells injury: involvement of PI3 kinase signal pathway," Acta Pharmacologica Sinica, vol. 30, no. 2, pp. 159-165, 2009.

[18] Y. Hao, C. Liu, F. Yin, Y. Zhang, and J. Liu, "5/-AMP-activated protein kinase plays an essential role in geniposide-regulated glucose-stimulated insulin secretion in rat pancreatic INS-1 $\beta$ cells," Journal of Natural Medicines, vol. 71, no. 1, pp. 123-130, 2017.

[19] J. H. Liu, L. X. Guo, F. Yin et al., "Geniposide regulates glucosestimulated insulin secretion possibly through controlling glucose metabolism in INS-1 cells," PLoS One, vol. 8, no. 10, article no. e78315, 2013.

[20] C. Y. Liu, Y. N. Hao, F. Yin, Y. L. Zhang, and J. H. Liu, "Geniposide accelerates proteasome degradation of Txnip to inhibit insulin secretion in pancreatic $\beta$-cells," Journal of Endocrinological Investigation, vol. 40, no. 5, pp. 505-512, 2017.

[21] L. X. Guo, J. H. Liu, and F. Yin, "Regulation of insulin secretion by geniposide: Possible involvement of phosphatidylinositol 3phosphate kinase," European Review for Medical and Pharmacological Sciences, vol. 18, no. 9, pp. 1287-1294, 2014.

[22] L. X. Guo, Z. N. Xia, G. Xue, Y. Fei, and J. H. Liu, "Glucagon-like peptide 1 receptor plays a critical role in geniposide-regulated insulin secretion in INS-1 cells," Acta Pharmacologica Sinica, vol. 33, no. 2, pp. 237-241, 2012.

[23] Y. Zhang, Y. Ding, X. Zhong et al., "Geniposide acutely stimulates insulin secretion in pancreatic $\beta$-cells by regulating GLP1 receptor/cAMP signaling and ion channels," Molecular and Cellular Endocrinology, vol. 430, pp. 89-96, 2016.

[24] C. Liu, Y. Hao, F. Yin, Y. Zhang, and J. Liu, "Geniposide protects pancreatic $\beta$ cells from high glucose-mediated injury by activation of AMP-activated protein kinase," Cell Biology International, vol. 41, no. 5, pp. 544-554, 2017.

[25] D. D. Yao, L. Yang, Y. Wang et al., "Geniposide promotes beta-cell regeneration and survival through regulating $\beta$ catenin/TCF7L2 pathway," Cell Death Disease, vol. 6, article no. e1746, 2015.

[26] J. Liu, F. Yin, H. Xiao, L. Guo, and X. Gao, "Glucagonlike peptide 1 receptor plays an essential role in geniposide attenuating lipotoxicity-induced $\beta$-cell apoptosis," Toxicology in Vitro, vol. 26, no. 7, pp. 1093-1097, 2012.

[27] Y. Zhang, F. Yin, J. Liu, and Y. Wang, "Geniposide protects pancreatic INS-1E $\beta$ cells from hIAPP-induced cell damage: 
Potential involvement of insulin degrading-enzyme," Cell Biology International, vol. 39, no. 4, pp. 373-378, 2015.

[28] Y. Zhang, F. Yin, J. Liu et al., "Geniposide attenuates insulin-deficiency-induced acceleration of $\beta$-amyloidosis in an APP/PS1 transgenic model of Alzheimer's disease," Neurochemistry International, vol. 89, pp. 7-16, 2015.

[29] S.-Y. Wu, G.-F. Wang, Z.-Q. Liu et al., "Effect of geniposide, a hypoglycemic glucoside, on hepatic regulating enzymes in diabetic mice induced by a high-fat diet and streptozotocin," Acta Pharmacologica Sinica, vol. 30, no. 2, pp. 202-208, 2009.

[30] L. Guo, X. Zheng, J. Liu, and Z. Yin, "Geniposide suppresses hepatic glucose production via AMPK in hepG2 cells," Biological \& Pharmaceutical Bulletin, vol. 39, no. 4, pp. 484-491, 2016.

[31] K. Kojima, T. Shimada, Y. Nagareda et al., "Preventive effect of geniposide on metabolic disease status in spontaneously obese type 2 diabetic mice and free fatty acid-treated HepG2 cells," Biological \& Pharmaceutical Bulletin, vol. 34, no. 10, pp. 16131618, 2011

[32] X. Hu, X. Zhang, G. Jin, Z. Shi, W. Sun, and F. Chen, "Geniposide reduces development of streptozotocin-induced diabetic nephropathy via regulating nuclear factor-kappa B signaling pathways," Fundamental \& Clinical Pharmacology, vol. 31, no. 1, pp. 54-63, 2017.

[33] G.-F. Wang, S.-Y. Wu, W. Xu et al., "Geniposide inhibits high glucose-induced cell adhesion through the NF-kappaB signaling pathway in human umbilical vein endothelial cells," Acta Pharmacologica Sinica, vol. 31, no. 8, pp. 953-962, 2010.

[34] Y. Chen, Y. Zhang, L. Li, and C. Hölscher, "Neuroprotective effects of geniposide in the MPTP mouse model of Parkinson's disease," European Journal of Pharmacology, vol. 768, pp. 21-27, 2015.

[35] C. Su, X. Yang, and J. Lou, "Geniposide reduces $\alpha$-synuclein by blocking microRNA-21/lysosome-associated membrane protein 2A interaction in Parkinson disease models," Brain Research, vol. 1644, pp. 98-106, 2016.

[36] H. Zhang, Q. Lai, Y. Li, Y. Liu, and M. Yang, "Learning and memory improvement and neuroprotection of Gardenia jasminoides (Fructus gardenia) extract on ischemic brain injury rats," Journal of Ethnopharmacology, vol. 196, pp. 225-235, 2017.

[37] B. Huang, P. Chen, L. Huang et al., "Geniposide Attenuates PostIschaemic Neurovascular Damage via GluN2A/AKT/ ERKDependent Mechanism," Cellular Physiology and Biochemistry, vol. 43, no. 2, pp. 705-716, 2017.

[38] Y.-P. Rong, H.-T. Huang, J.-S. Liu, and L. Wei, "Protective Effects of Geniposide on Hepatic Ischemia/Reperfusion Injury," Transplantation Proceedings, vol. 49, no. 6, pp. 1455-1460, 2017.

[39] J. Wang, J. Hou, P. Zhang, D. Li, C. Zhang, and J. Liu, “Geniposide reduces inflammatory responses of oxygen-glucose deprived rat microglial cells via inhibition of the TLR4 signaling pathway," Neurochemical Research, vol. 37, no. 10, pp. 2235-2248, 2012.

[40] F. Li, W. Li, X. Li et al., "Geniposide attenuates inflammatory response by suppressing P2Y14 receptor and downstream ERK1/2 signaling pathway in oxygen and glucose deprivationinduced brain microvascular endothelial cells," Journal of Ethnopharmacology, vol. 185, pp. 77-86, 2016.

[41] P. Lee, J. Lee, S. Y. Choi, S. E. Lee, S. Lee, and D. Son, "Geniposide from Gardenia jasminoides attenuates neuronal cell death in oxygen and glucose deprivation-exposed rat hippocampal slice culture," Biological \& Pharmaceutical Bulletin, vol. 29, no. 1, pp. 174-176, 2006.
[42] Z.-Y. Huang, B.-B. Pan, C.-Y. Huang et al., "Screening of Active Fractions from Huanglian Jiedu Decoction against Primary Neuron Injury after Oxygen-Glucose Deprivation," Zhongguo Zhong Xi Yi Jie He Za Zhi Zhongguo Zhongxiyi Jiehe Zazhi, vol. 35, no. 8, pp. 981-987, 2015.

[43] Y.-Q. Jiang, G.-L. Chang, Y. Wang, D.-Y. Zhang, L. Cao, and J. Liu, "Geniposide Prevents Hypoxia/Reoxygenation-Induced Apoptosis in H9c2 Cells: Improvement of Mitochondrial Dysfunction and Activation of GLP-1R and the PI3K/AKT Signaling Pathway," Cellular Physiology and Biochemistry, vol. 39, no. 1, pp. 407-421, 2016.

[44] T. Zhang, A. Zhang, S. Qiu et al., "High-throughput metabolomics approach reveals new mechanistic insights for drug response of phenotypes of geniposide towards alcohol-induced liver injury by using liquid chromatography coupled to high resolution mass spectrometry," Molecular BioSystems, vol. 13, no. 1, pp. 73-82, 2017.

[45] J. Wang, Y. Zhang, R. Liu, X. Li, Y. Cui, and L. Qu, "Geniposide protects against acute alcohol-induced liver injury in mice via up-regulating the expression of the main antioxidant enzymes," Canadian Journal of Physiology and Pharmacology, vol. 93, no. 4, pp. 261-267, 2015.

[46] T. Ma, C. Huang, G. Zong et al., "Hepatoprotective effects of geniposide in a rat model of nonalcoholic steatohepatitis," Journal of Pharmacy and Pharmacology, vol. 63, no. 4, pp. 587593, 2011.

[47] L. Wang, G. Wu, F. Wu, N. Jiang, and Y. Lin, "Geniposide attenuates ANIT-induced cholestasis through regulation of transporters and enzymes involved in bile acids homeostasis in rats," Journal of Ethnopharmacology, vol. 196, pp. 178-185, 2017.

[48] Z. Tan, A. Liu, M. Luo et al., "Geniposide inhibits $\alpha$-naphthylisothiocyanate-induced intrahepatic cholestasis: the downregulation of STAT3 and NFkB signaling plays an important role," American Journal of Chinese Medicine, vol. 44, no. 4, pp. 721736, 2016.

[49] J. Wang, M. Miao, L. Qu, Y. Cui, and Y. Zhang, "Protective effects of geniposide against Tripterygium glycosides (TG)-induced liver injury and its mechanisms," Journal of Toxicological Sciences, vol. 41, no. 1, pp. 165-173, 2016.

[50] H.-Y. Lee, G.-H. Lee, M.-R. Lee et al., "Eucommia ulmoides Oliver extract, aucubin, and geniposide enhance lysosomal activity to regulate ER stress and hepatic lipid accumulation," PLoS ONE, vol. 8, no. 12, 2013.

[51] G.-H. Lee, M.-R. Lee, H.-Y. Lee et al., "Eucommia ulmoides cortex, geniposide and aucubin regulate lipotoxicity through the inhibition of lysosomal BAX," PLoS ONE, vol. 9, no. 2, 2014.

[52] J.-H. Park, J. Yoon, K. Y. Lee, and B. Park, "Effects of geniposide on hepatocytes undergoing epithelial-mesenchymal transition in hepatic fibrosis by targeting TGF $\beta /$ Smad and ERK-MAPK signaling pathways," Biochimie, vol. 113, article no. 4678, pp. 2634, 2015.

[53] M. M. Dai, H. Wu, H. Li et al., "Effects and mechanisms of Geniposide on rats with adjuvant arthritis," International Immunopharmacology, vol. 20, no. 1, pp. 46-53, 2014.

[54] Z.-R. Zhang, H. Wu, R. Wang, S.-P. Li, L. Dai, and W.-Y. Wang, "Immune tolerance effect in mesenteric lymph node lymphocytes of geniposide on adjuvant arthritis rats," Phytotherapy Research, vol. 31, no. 8, pp. 1249-1256, 2017.

[55] J. Y. Chen, H. Wu, H. Li, S. L. Hu, M. M. Dai, and J. Chen, "Anti-inflammatory effects and pharmacokinetics study of geniposide on rats with adjuvant arthritis," International Immunopharmacology, vol. 24, no. 1, pp. 102-109, 2015. 
[56] R. Wang, H. Wu, J. Chen et al., "Antiinflammation effects and mechanisms study of geniposide on rats with collagen-induced arthritis," Phytotherapy Research, vol. 31, no. 4, pp. 631-637, 2017.

[57] X. Song, W. Zhang, T. Wang et al., "Geniposide plays an anti-inflammatory role via regulating TLR4 and downstream signaling pathways in lipopolysaccharide-induced mastitis in mice," Inflammation, vol. 37, no. 5, pp. 1588-1598, 2014.

[58] C.-H. Chang, J.-B. Wu, J.-S. Yang et al., “The suppressive effects of geniposide and genipin on helicobacter pylori infections in vitro and in vivo," Journal of Food Science, vol. 82, no. 12, pp. 3021-3028, 2017.

[59] Z. Zhang, Y. Li, P. Shen et al., "Administration of geniposide ameliorates dextran sulfate sodium-induced colitis in mice via inhibition of inflammation and mucosal damage," International Immunopharmacology, vol. 49, pp. 168-177, 2017.

[60] B. Xu, Y. L. Li, M. Xu et al., "Geniposide ameliorates TNBSinduced experimental colitis in rats via reducing inflammatory cytokine release and restoring impaired intestinal barrier function," Acta Pharmacologica Sinica, vol. 38, no. 5, pp. 688-698, 2017.

[61] T.-T. Ma, X.-F. Li, W.-X. Li et al., "Geniposide alleviates inflammation by suppressing $\mathrm{MeCP} 2$ in mice with carbon tetrachloride-induced acute liver injury and LPS-treated THP1 cells," International Immunopharmacology, vol. 29, no. 2, pp. 739-747, 2015.

[62] X.-F. Yang, Q.-R. Cai, J.-P. He et al., "Geniposide, an iridoid glucoside derived from gardenia jasminoides, protects against lipopolysaccharide-induced acute lung injury in mice," Planta Medica, vol. 78, no. 6, pp. 557-564, 2012.

[63] Y. Fu, B. Liu, J. Liu et al., "Geniposide, from Gardenia jasminoides Ellis, inhibits the inflammatory response in the primary mouse macrophages and mouse models," International Immunopharmacology, vol. 14, no. 4, pp. 792-798, 2012.

[64] G. Zhang, J.-L. He, X.-Y. Xie, and C. Yu, "LPS-induced iNOS expression in N9 microglial cells is suppressed by geniposide via ERK, p38 and nuclear factor- $\kappa$ B signaling pathways," International Journal of Molecular Medicine, vol. 30, no. 3, pp. 561$568,2012$.

[65] L. Huang, C. Wang, G. Naren, and G. Aori, "Effect of geniposide on LPS-induced activation of TLR4-NF- $\kappa$ B pathway in RAW264.7 macrophage cell line," Chinese Journal of Cellular And Molecular Immunology, vol. 29, no. 10, pp. 1012-1014, 2013.

[66] L.-H. Huang, X.-P. Pan, K.-R. Gong, and G. Shao, "Antiinflammatory effects of three kinds of traditional Mongolian medicine monomer and its combination on LPS-stimulated RAW264.7 macrophages," European Review for Medical and Pharmacological Sciences, vol. 20, no. 5, pp. 950-958, 2016.

[67] Q. Shi, J. Cao, L. Fang et al., "Geniposide suppresses LPSinduced nitric oxide, $\mathrm{PGE}_{2}$ and inflammatory cytokine by downregulating NF- $\kappa \mathrm{B}, \mathrm{MAPK}$ and AP-1 signaling pathways in macrophages," International Immunopharmacology, vol. 20, no. 2, pp. 298-306, 2014.

[68] H.-T. Liu, J.-L. He, W.-M. Li et al., "Geniposide inhibits interleukin-6 and interleukin-8 production in lipopolysaccharide-induced human umbilical vein endothelial cells by blocking p38 and ERK1/2 signaling pathways," Inflammation Research, vol. 59, no. 6, pp. 451-461, 2010.

[69] L. Cai, R. Li, W.-J. Tang, G. Meng, X.-Y. Hu, and T.$\mathrm{N}$. Wu, "Antidepressant-like effect of geniposide on chronic unpredictable mild stress-induced depressive rats by regulating the hypothalamus-pituitary-adrenal axis," European Neuropsychopharmacology, vol. 25, no. 8, pp. 1332-1341, 2015.
[70] J. Wang, P. Duan, Y. Cui, Q. Li, and Y. Shi, “Geniposide alleviates depression-like behavior via enhancing BDNF expression in hippocampus of streptozotocin-evoked mice," Metabolic Brain Disease, vol. 31, no. 5, pp. 1113-1122, 2016.

[71] F. Yin, J. Liu, X. Zheng, L. Guo, and H. Xiao, "Geniposide induces the expression of heme oxygenase-1 via PI3K/Nrf2signaling to enhance the antioxidant capacity in primary hippocampal neurons," Biological \& Pharmaceutical Bulletin, vol. 33, no. 11, pp. 1841-1846, 2010.

[72] F. Yin, J. H. Liu, X. X. Zheng, and L. X. Guo, "GLP-1 receptor plays a critical role in geniposide-induced expression of heme oxygenase-1 in PC12 cells," Acta Pharmacologica Sinica, vol. 31, no. 5, pp. 540-545, 2010.

[73] W. J. Chen, T. Z. Bao, K. Chen et al., "Effects of geniposide on SNP-induced apoptosis of chondrocyte and cell cycle," China Journal of Orthopaedics and Traumatology, vol. 26, no. 3, pp. 232-235, 2013.

[74] X. Song, M. Guo, T. Wang, W. Wang, Y. Cao, and N. Zhang, "Geniposide inhibited lipopolysaccharide-induced apoptosis by modulating TLR4 and apoptosis-related factors in mouse mammary glands," Life Sciences, vol. 119, no. 1-2, pp. 9-17, 2014.

[75] L.-X. Guo, J.-H. Liu, and Z.-N. Xia, "Geniposide inhibits CoCl2induced PC12 cells death via the mitochondrial pathway," Chinese Medical Journal, vol. 122, no. 23, pp. 2886-2892, 2009.

[76] L. Liu, P. Liao, B. Wang, X. Fang, W. Li, and S. Guan, "Oral administration of baicalin and geniposide induces regression of atherosclerosis via inhibiting dendritic cells in ApoE-knockout mice," International Immunopharmacology, vol. 20, no. 1, pp. 197-204, 2014.

[77] P. Liao, L. Liu, B. Wang, W. Li, X. Fang, and S. Guan, "Baicalin and geniposide attenuate atherosclerosis involving lipids regulation and immunoregulation in ApoE-/- mice," European Journal of Pharmacology, vol. 740, pp. 488-495, 2014.

[78] X. Zheng, D. Yang, X. Liu et al., "Identification of a new antiLPS agent, geniposide, from Gardenia jasminoides Ellis, and its ability of direct binding and neutralization of lipopolysaccharide in vitro and in vivo," International Immunopharmacology, vol. 10, no. 10, pp. 1209-1219, 2010.

[79] G.-R. Chen, G. Zhang, M.-Y. Li et al., "The effective components of Huanglian Jiedu Decoction against sepsis evaluated by a lipid A-based affinity biosensor," Journal of Ethnopharmacology, vol. 186, pp. 369-376, 2016.

[80] Z.-G. Ma, J. Dai, W.-B. Zhang et al., "Protection against cardiac hypertrophy by geniposide involves the GLP-1 receptor / AMPK $\alpha$ signalling pathway," British Journal of Pharmacology, vol. 173, no. 9, pp. 1502-1516, 2016.

[81] N. Gong, H. Fan, A.-N. Ma, Q. Xiao, and Y.-X. Wang, "Geniposide and its iridoid analogs exhibit antinociception by acting at the spinal GLP-1 receptors," Neuropharmacology, vol. 84, pp. 31-45, 2014.

[82] R. Li, L. Cai, W.-J. Tang, C. Lei, C.-M. Hu, and F. Yu, "Apoptotic effect of geniposide on fibroblast-like synoviocytes in rats with adjuvant-induced arthritis via inhibiting erk signal pathway in vitro," Inflammation, vol. 39, no. 1, pp. 30-38, 2016.

[83] H.-Y. Zhang, H. Liu, M. Yang, and S.-F. Wei, "Antithrombotic activities of aqueous extract from Gardenia jasminoides and its main constituent," Pharmaceutical Biology, vol. 51, no. 2, pp. 221-225, 2013.

[84] Y.-J. Lin, C.-C. Lai, C.-H. Lai et al., "Inhibition of enterovirus 71 infections and viral IRES activity by Fructus gardeniae and geniposide," European Journal of Medicinal Chemistry, vol. 62, pp. 206-213, 2013. 
[85] W.-J. Lan, H.-Y. Wang, W. Lan, and K.-Y. Wang, "Geniposide enhances melanogenesis by stem cell factor/c-kit signalling in norepinephrine-exposed normal human epidermal melanocyte," Basic \& Clinical Pharmacology \& Toxicology, vol. 103, no. 1, pp. 88-93, 2008.

[86] M. Gálvez, C. Martín-Cordero, and M. J. Ayuso, "Iridoids as DNA topoisomers I poisons," Journal of Enzyme Inhibition and Medicinal Chemistry, vol. 20, no. 4, pp. 389-392, 2005.

[87] K. Qu, L. Zhao, X. Luo et al., "An LC-MS method for simultaneous determination of five iridoids from Zhi-zi-chi Decoction in rat brain microdialysates and tissue homogenates: Towards an in depth study for its antidepressive activity," Journal of Chromatography B, vol. 965, pp. 206-215, 2014.

[88] Z.-Z. Chen, Y. Lu, S.-Y. Du, K.-X. Shang, and C.-B. Cai, "Influence of borneol and muscone on geniposide transport through MDCK and MDCK-MDR1 cells as blood-brain barrier in vitro model.," International Journal of Pharmaceutics, vol. 456, no. 1, pp. 73-79, 2013.

[89] X. Che, M. Wang, T. Wang et al., "Evaluation of the antidepressant activity, hepatotoxicity and blood brain barrier permeability of methyl genipin," Molecules, vol. 21, no. 7, article no. E923, 2016.

[90] B. Yu, M. Ruan, X.-B. Cui, J.-M. Guo, L. Xu, and X.-P. Dong, "Effects of borneol on the pharmacokinetics of geniposide in cortex, hippocampus, hypothalamus and striatum of conscious rat by simultaneous brain microdialysis coupled with UPLC-MS," Journal of Pharmaceutical and Biomedical Analysis, vol. 77, pp. 128-132, 2013.

[91] Y. Ding, T. Zhang, J.-S. Tao, L.-Y. Zhang, J.-R. Shi, and G. Ji, "Potential hepatotoxicity of geniposide, the major iridoid glycoside in dried ripe fruits of Gardenia jasminoides (Zhi-zi)," Natural Product Research (Formerly Natural Product Letters), vol. 27, no. 10, pp. 929-933, 2013.

[92] J. Wei, F. Zhang, Y. Zhang et al., "Proteomic investigation of signatures for geniposide-induced hepatotoxicity," Journal of Proteome Research, vol. 13, no. 12, pp. 5724-5733, 2014.

[93] J. Tian, Y. Yi, Y. Zhao et al., "Oral chronic toxicity study of geniposide in rats," Journal of Ethnopharmacology, vol. 213, pp. 166-175, 2018. 


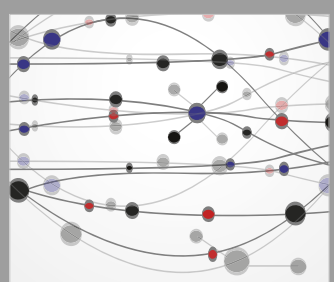

The Scientific World Journal
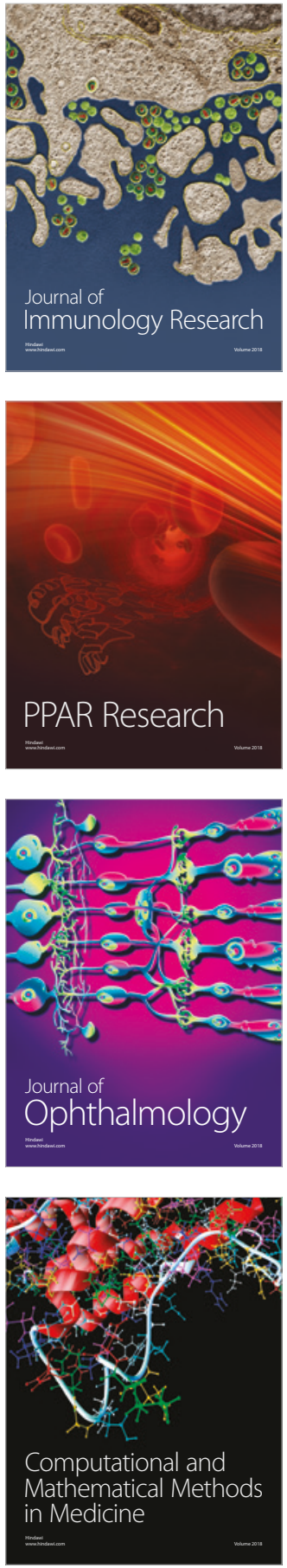

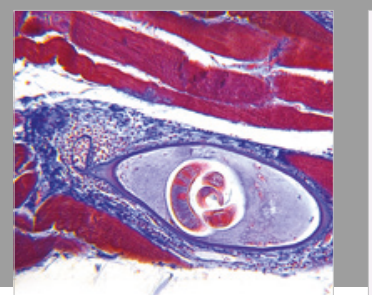

Gastroenterology Research and Practice

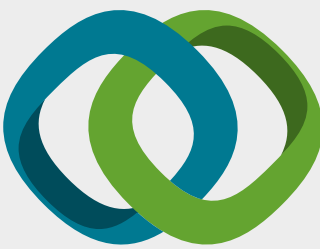

\section{Hindawi}

Submit your manuscripts at

www.hindawi.com
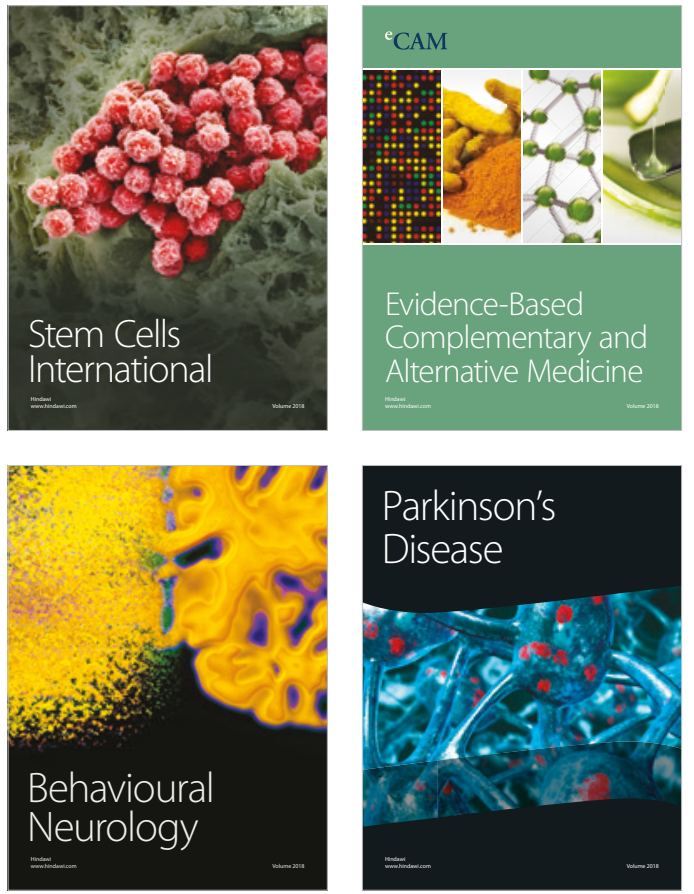

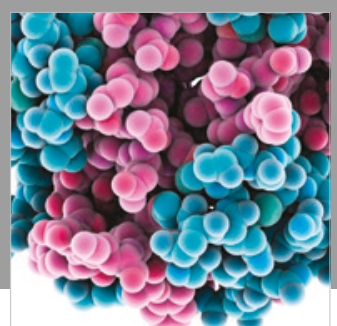

ournal of

Diabetes Research

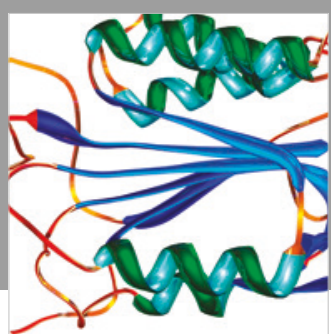

Disease Markers
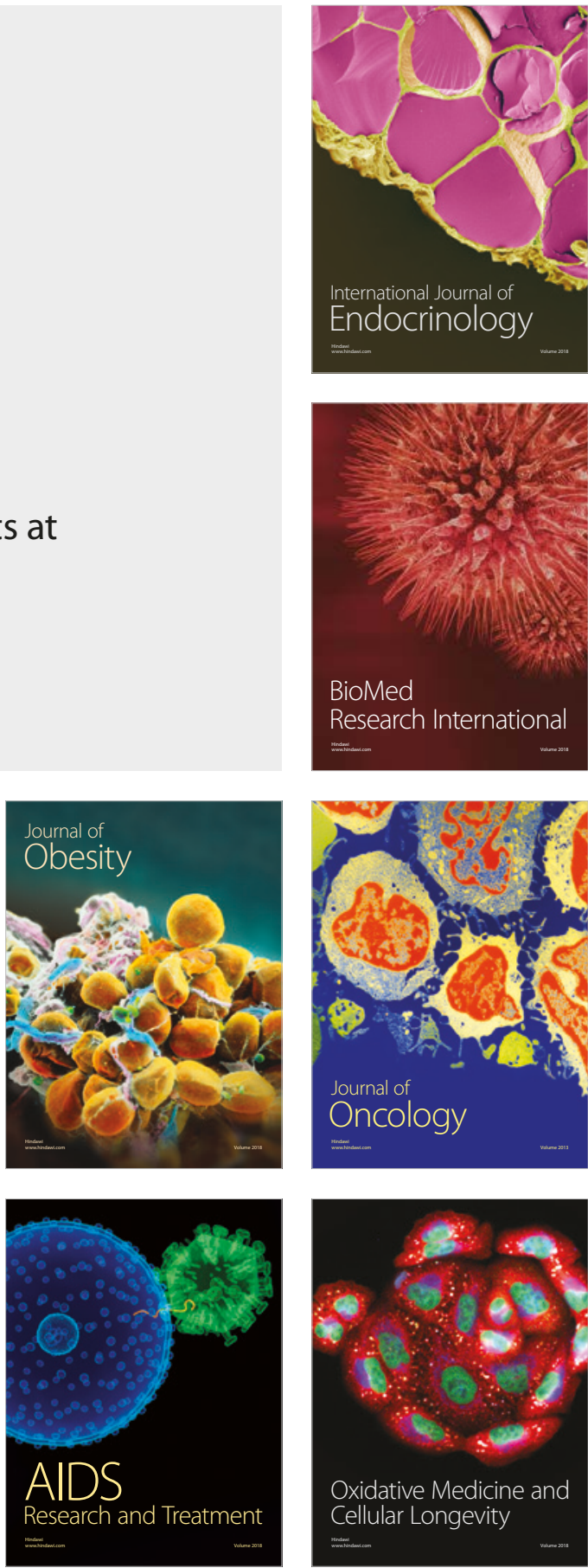